\title{
Variação sazonal de clorofilas em folhas de Tabebuia avellanedae e Anadenanthera colubrina
}

\author{
Seasonal chlorophyll variations in \\ Tabebuia avellanedae and Anadenanthera colubrine leaves
}

\author{
Mariângela Brito Freiberger ${ }^{*}$; Gustavo Castoldi²; Deniele Marini ${ }^{3}$; Aleteia Lang \\ Neusa Francisca Michelon Herzog ${ }^{5}$; Ubirajara Contro Malavasi ${ }^{6}$
}

\begin{abstract}
Resumo
O estudo avaliou a variação sazonal das concentrações de clorofilas a, b e total, e da razão clorofila a/b em folhas de Anadenanthera colubrina e Tabebuia avellanedae. O experimento foi implantado em blocos casualizados arranjados em esquema fatorial $2 \times 3$ (duas espécies e três épocas de avaliação), com cinco repetições. A concentração de clorofilas nas folhas foi determinada ao final do inverno, final primavera e final do verão. $\mathrm{O}$ teor de clorofila a sofreu alteração apenas em folhas de A. colubrina, aumentando do final da primavera $\left(117,52 \mu \mathrm{g} \mathrm{mL}^{-1}\right)$ ao final do verão $\left(151,13 \mu \mathrm{g} \mathrm{mL}^{-1}\right)$. Para as duas espécies, a proporção de clorofila b foi maior entre os períodos do final da primavera (média de 29,31 $\mu \mathrm{g}$ $\mathrm{mL}^{-1}$ ) ao final do verão (média de $74,96 \mu \mathrm{g} \mathrm{mL}^{-1}$ ), o qual apresentou estreita relação com a diminuição na irradiância solar global. A relação clorofila a/b aumentou no final da primavera em função da redução da clorofila b. A. colubrina mostrou maior aclimatação no ambiente estudado.
\end{abstract}

Palavras-chave: Aclimatação, espécies heliófitas, luminosidade

\begin{abstract}
The experiment had the aim of quantifying seasonal chlorophyll variation on leaves of Anadenanthera colubrina and Tabebuia avellanedae. The experiment used a randomized block design established as a 2 x 3 factorial (two species and three sampling seasons) with 5 replications. The concentrations of chlorophyll in leaves were performed at the end of winter, late spring, and summer. The content of chlorophyll a changed only for $A$. colubrina, bringing up from spring $\left(117.52 \mu \mathrm{g} \mathrm{mL}^{-1}\right)$ to summer $\left(151.13 \mu \mathrm{g} \mathrm{mL}^{-1}\right)$. For the two species, the proportion of chlorophyll $\mathrm{b}$ was higher between periods at the end of spring (average of $29.31 \mu \mathrm{g} \mathrm{mL}^{-1}$ ) to the end of summer (average of $74.96 \mu \mathrm{g} \mathrm{mL}^{-1}$ ) with close relationship with the decrease in global solar irradiance. The chlorophyll a/b relationship increased in late spring due to reduction of chlorophyll $\mathrm{b}$ content. A. colubrina showed greater adaptation to the studied environment.
\end{abstract}

Key words: Acclimation, heliophytic species, luminosity

\footnotetext{
${ }^{1}$ Mestranda em Ciência Florestal, Faculdade de Ciências Agronômicas da Universidade Estadual Paulista, FCA/UNESP. Rua José Barbosa de Barros, 1780. Cx. Postal 237 CEP 18610-370. Botucatu, SP. E-mail: mariangelabf@fca.unep.br

2 Mestrando em Agronomia/Agricultura, FCA/UNESP, Botucatu, SP. E-mail: g_castoldi@fca.unesp.br

${ }^{3}$ Mestranda em Produção Vegetal, Universidade Estadual do Oeste do Paraná, UNIOESTE. Rua Pernambuco, 1777. Cx. Postal 1008 CEP 85960-000. Marechal Cândido Rondon - PR. E-mail: denimarini@hotmail.com

${ }^{4}$ Mestre em Produção Vegetal, UNIOESTE, Marechal Cândido Rondon, PR. E-mail: teialang@hotmail.com

${ }^{5}$ Doutoranda em Produção vegetal, UNIOESTE, Marechal Cândido Rondon, PR. E-mail: hrzmch@gmail.com

${ }^{6}$ Prof. Adjunto do Centro de Ciências Agrárias, UNIOESTE, Marechal Cândido Rondon, PR. E-mail: biramalavasi@yahoo.com. br

* Autor para correspondência
} 
Plântulas crescendo no interior de uma floresta passam por mudanças bruscas na quantidade de luz que recebem e estão sujeitas a incidências de luz que variam com as horas do dia, com as estações do ano, com a movimentação de copas e queda de outras plantas ao redor (OSUNKOYA; ASH, 1991). A adaptação das plantas à quantidade, qualidade, presença ou ausência de luz durante a fase inicial do seu desenvolvimento condiciona mudanças em sua estrutura e metabolismo, determinando o sucesso ou não do crescimento da espécie florestal (INOUE, 1977). Esta adaptação depende do ajuste de seu sistema fotossintético, de modo que a luminosidade ambiental seja utilizada de maneira mais eficiente possível (ENGEL; POGGIANI, 1991), expressando características de sua plasticidade fenotípica (SMITH, 1982).

A combinação das clorofilas a e b e dos pigmentos acessórios capacita as plantas a captarem a maior parte de energia disponível da luz solar pela ativação do seu sistema fotossintético (TAIZ; ZAIGER, 2004), podendo ser utilizados como parâmetros indicativos de estresses abióticos nas plantas (CODOGNOTTO et al., 2002). Este trabalho objetivou quantificar a variação sazonal das concentrações de clorofilas a, b e total, e da razão clorofila a/b em folhas de Anadenanthera colubrina (angico branco) e Tabebuia avellanedae (ipê-roxo), espécies indicadas para a arborização e para o plantio em florestas mistas destinadas à revegetação de áreas de preservação permanente.

$\mathrm{O}$ experimento foi instalado em área de domínio ciliar no município de Palotina - PR, localizado a $24^{\circ} 20^{\prime} \mathrm{S}$ e $53^{\circ} 50^{\prime} \mathrm{W}$, com altitude de 330 metros e temperatura média anual de $21,3{ }^{\circ} \mathrm{C}$ (IAPAR, 2008). O clima local é subtropical (Cfa), sem estação seca definida e o solo predominante na área é o Latossolo Vermelho eutroférrico, de textura muito argilosa com relevo plano (EMBRAPA, 2006). Mudas de angico branco e ipê-roxo com 120 dias de idade foram transplantadas para a área experimental no dia 20 de outubro de 2006. O delineamento experimental adotado foi o de blocos casualizados, arranjados em esquema fatorial 2 × 3 (2 espécies e 3 épocas de avaliação) com 5 repetições. Cada bloco era formado por 16 plantas de angico branco, dispostas em quatro linhas contendo quatro plantas cada, e 16 plantas de ipê-roxo, dispostas da mesma forma num espaçamento de 2 × $2 \mathrm{~m}$. Nas datas de 06 de setembro de 2007 (final de inverno), 05 de dezembro de 2007 (final de primavera) e 14 de março de 2008 (final de verão), coletou-se três folhas completamente expandidas, não sombreadas e sadias do terço médio da copa das quatro árvores centrais de cada espécie, em cada bloco. A irradiância solar global nas datas de coleta, as quais eram realizadas entre às 8 e às 10 horas da manhã, correspondiam respectivamente a 13, 19 e $17 \mathrm{MJ}$ $\mathrm{m}^{-2} \mathrm{dia}^{-2}$ (IAPAR, 2008). Na data da primeira coleta as árvores estavam com aproximadamente um ano de idade (10 meses e 17 dias) e comprimento médio de $2,10 \mathrm{~m}$.

A extração de clorofila das folhas foi realizada segundo a metodologia de Arnon (1949) realizandose, posteriormente, a leitura das soluções extraídas em espectrofotômetro analógico (Spectrumlab 22) a 435 e 643 nanômetros. Os valores das leituras foram utilizados em equações propostas por Porra (2002), obtendo-se então as concentrações de clorofilas $\mathrm{a}, \mathrm{b}$ e total, em $\mu \mathrm{g} \mathrm{mL}^{-1}$ de solução. Os resultados obtidos foram submetidos à análise de variância utilizando-se o programa SISVAR (FERREIRA, 2000) e quando verificadas diferenças significativas, as médias foram comparadas pelo teste de Tukey ao nível de $5 \%$.

A análise dos resultados evidenciou interações significativas $(p<0,01)$ entre as épocas de avaliação e as espécies para todas as variáveis mensuradas. As folhas de angico branco apresentaram menores concentrações de clorofila a e b no final do inverno e da primavera, havendo aumento destas concentrações no final de verão (Tabela 1), uma vez que, comumente o que se observa nas plantas, é a ocorrência de uma queda do teor de pigmentos no inverno (GERUM; INOUE, 1995). Todavia, folhas de ipê roxo apresentaram 1,5 vezes mais clorofila $b$ 
em setembro (final de inverno), quando a irradiância solar global média era 1,5 vezes menor em relação à irradiância em dezembro (final de primavera). Este comportamento encontra respaldo em estudos realizados por Almeida et al. (2004), os quais afirmam que, para algumas espécies, pode ocorrer um maior acúmulo de clorofilas sob baixa radiação solar devido ao efeito compensatório desta espécie à menor quantidade de radiação disponível.
Com relação à concentração de clorofila a em folhas de ipê roxo, não houve variação significativa ( $>00,05)$ em função da variação luminosa sazonal (Tabela 1), provavelmente pelo fato de que a clorofila a está presente tanto no complexo P-700clorofila a-proteína, como no complexo a/b-proteína, os quais variam diferentemente com a ação da luz, enquanto que a clorofila $b$ tem uma resposta mais definida (YODER; DALEY, 1990).

Tabela 1. Valores médios da concentração $\left(\mu \mathrm{g} \mathrm{mL}^{-1}\right)$ de clorofilas $\mathrm{a}, \mathrm{b}$ e total e da razão clorofila a/b em função das espécies e épocas de avaliação. Palotina - PR, 2007/2008.

\begin{tabular}{|c|c|c|c|c|c|c|}
\hline Épocas de avaliação & Angico branco & & & Ipê-roxo & & \\
\hline & \multicolumn{6}{|c|}{ Clorofila $a$} \\
\hline & Concentração & & & Concentração & & \\
\hline Final do inverno & 93,147 & B & $\mathrm{a}$ & 96,99 & $\mathrm{~A}$ & $\mathrm{a}$ \\
\hline Final da primavera & 117,52 & B & $\mathrm{a}$ & 96,77 & A & $\mathrm{a}$ \\
\hline \multirow[t]{3}{*}{ Final do verão } & 151,13 & A & $\mathrm{a}$ & 88,84 & $\mathrm{~A}$ & $\mathrm{~b}$ \\
\hline & \multicolumn{6}{|c|}{ Clorofila $b$} \\
\hline & Concentração & & & Concentração & & \\
\hline Final do inverno & 27,21 & B & $\mathrm{a}$ & 46,56 & $\mathrm{AB}$ & $\mathrm{a}$ \\
\hline Final da primavera & 26,72 & B & $\mathrm{a}$ & 31,88 & $\mathrm{~B}$ & $\mathrm{a}$ \\
\hline \multirow[t]{3}{*}{ Final do verão } & 97,47 & A & $\mathrm{a}$ & 62,31 & A & $\mathrm{b}$ \\
\hline & \multicolumn{6}{|c|}{ Clorofila total } \\
\hline & Concentração & & & Concentração & & \\
\hline Final do inverno & 120,36 & B & $\mathrm{a}$ & 143,56 & A & $\mathrm{a}$ \\
\hline Final da primavera & 144,25 & B & $\mathrm{a}$ & 128,66 & A & $\mathrm{a}$ \\
\hline \multirow[t]{3}{*}{ Final do verão } & 240,45 & A & $\mathrm{a}$ & 151,12 & A & $\mathrm{b}$ \\
\hline & \multicolumn{6}{|c|}{ Razão clorofila $a / b$} \\
\hline & Concentração & & & Concentração & & \\
\hline Final do inverno & 3,76 & B & $\mathrm{a}$ & 2,96 & $\mathrm{AB}$ & $\mathrm{a}$ \\
\hline Final da primavera & 5,16 & A & $\mathrm{a}$ & 3,81 & A & $\mathrm{b}$ \\
\hline Final do verão & 1,78 & $\mathrm{C}$ & $\mathrm{a}$ & 1,99 & $\mathrm{~B}$ & $\mathrm{a}$ \\
\hline
\end{tabular}

*Médias seguidas da mesma letra minúscula nas linhas e maiúscula nas colunas não diferem entre si pelo teste de Tukey ao nível de $5 \%$.

A concentração de clorofila total em folhas de angico branco aumentou significativamente na amostragem realizada em março (final de verão), quando a irradiância solar global média foi de 17 MJ m dia $^{-1}$. Contudo, em folhas de ipê-roxo não se detectou diferença significativa $(\mathrm{p}<0,05)$ para a concentração de clorofila total, provavelmente pelo fato da inexistência de variação na concentração de clorofila a. No mês de março (final do verão) verificou-se diferença significativa entre as duas 
espécies, quando folhas de angico apresentavam 1,6 vezes mais clorofila total.

Considerando que as espécies estudadas são heliófitas e que apenas o angico branco apresentou diferença significativa para a concentração de clorofila total ao final do verão, pode-se inferir que esta é mais responsiva ao aumento da intensidade luminosa. Este comportamento reflete a característica pioneira da espécie, enquanto que o ipê roxo apresenta maior produtividade em formações secundárias ou primárias densas (LORENZI, 1992).

Os números na Tabela 1 evidenciam que, para as duas espécies estudadas, a razão clorofila a/b foi maior ao final da primavera, o que é explicado pelo aumento na irradiância de 13 para $19 \mathrm{MJ} \mathrm{m}^{-2} \mathrm{dia}^{-1}$ no período, acarretando em redução da concentração de clorofila b. Nota-se também que entre a segunda e a terceira quantificação houve um decréscimo significativo $(p<0,05)$ da razão clorofila $a / b$, uma vez que, neste intervalo, ocorreu um aumento do teor de clorofila b com redução da irradiância de 19 para $17 \mathrm{MJ} \mathrm{m}^{-2} \mathrm{dia}^{-1}$.

A relação clorofila $a / b$ tende a diminuir com a redução da intensidade luminosa devido a uma maior proporção relativa de clorofila $b$ em ambiente com menor incidência de luz (ENGEL; POGGIANI, 1991). Contudo, o teor de clorofila b em folhas de angico branco foi 3,6 vezes inferior no final do inverno, em comparação ao final do verão, quando as irradiâncias correspondiam a $13 \mathrm{MJ} \mathrm{m}^{-2} \mathrm{dia}^{-1}$ e 17 $\mathrm{MJ} \mathrm{m}^{-2} \mathrm{dia}^{-1}$, respectivamente.

Conclui-se que o angico branco é uma espécie responsiva ao aumento da irradiância solar, uma vez que apresentou elevação na concentração de clorofila total durante as estações estudadas, diferentemente do ipê-roxo, que manteve constante o teor total de clorofila independentemente da época de avaliação.

\section{Referências}

ALMEIDA, L. P.; ALVARENGA, A. A.; CASTRO, E. M.; ZANELA, S. M.; VIEIRA, C. V. Crescimento inicial de plantas de Cryptocaria aschersoniana Mez. submetidas a níveis de radiação solar. Ciência Rural, Santa Maria, v. 34, n. 1, p. 83-88, 2004.

ARNON, D. I. Cooper enzymes in isolated chloroplasts. Polyphenoloxidase in Beta vulgaris. Plant Physiology, Bethesda, v. 24, n. 1, p. 1-15, 1949.

CODOGNOTTO, L. M.; SANTOS, D. M. M.; LEITE, I. C.; MARIN, A.; MADALENO, L. L.; KOBORI, N. N.; BANZATTO, D. A. Efeito do alumínio nos teores de clorofilas de plântulas de feijão-mungo e labe-labe. Ecossistema, Espírito Santo do Pinhal, v. 27, n. 1, p. 2730, 2002.

EMPRESA BRASILEIRA DE PESQUISA AGROPECUÁRIA - EMBRAPA. Centro Nacional de Pesquisa de Solos (Rio de Janeiro, RJ). Sistema brasileiro de classificação de solos. Brasília: EMBRAPA-SPI/ EMBRAPA-CNPS, 2006. 412 p.

ENGEL, V. L.; POGGIANI, F. Estudo da concentração de clorofila nas folhas e seu espectro de absorção de luz em função do sombreamento em mudas de quatro espécies florestais nativas. Revista Brasileira de Fisiologia, Londrina, v. 3, n. 1, p. 39-45, 1991.

FERREIRA, D. F. Análises estatísticas por meio do Sisvar para Windows versão 4.0. In: REUNIÃO ANUAL DA REGIÃO BRASILEIRA DA SOCIEDADE INTERNACIONAL DE BIOMETRIA, 45., 2000, São Carlos. Anais... São Carlos:UFSCar, 2000. p. 255-258.

GERUM, M.; INOUE, M. T. Variação estacional da pigmentação foliar de quatro espécies arbóreas em função da poluição urbana. In: CONGRESSO BRASILEIRO DE FISIOLOGIA VEGETAL, 5., 1995, Lavras, MG.. Anais... Lavras: SBFV/UFL, 1995. 278 p.

INSTITUTO AGRONÔMICO DO APRANÁ - IAPAR. Médias históricas em estações do IAPAR. 2008. Disponível em: <www.iapar.br/modules/conteudo/ conteudo.php?conteudo=668>. Acesso em: 19 set. 2008.

INOUE, M. T. A auto-ecologia do gênero Cedrela: efeitos da fisiologia do crescimento no estágio juvenil em função da intensidade luminosa. Revista Floresta, Curitiba, v. 8, n. 2, p. 58-61, 1977.

LORENZI, H. Árvores brasileiras: manual de identificação e cultivo de plantas arbóreas nativas do Brasil. Nova Odessa: Plantarum, 1992. 352 p. 
OSUNKOYA, O. O.; ASH, J. E. Acclimation to a change in light regime in seedlings of six Australian rainforest tree species. Australian Journal of Botany, Melbourne, v. 39, n. 6, p. 591-605, 1991.

PORRA, R. J. The chequered history of the development and use of simultaneous equations for the accurate determination of chlorophylls a and b. Photosynthesis Research, Netherlands, v. 73, n. 3, p. 149-156, 2002.
SMITH, H. Light quality, photoperception, and plant strategy. Annual Review of Plant Physiology, Palo Alto, v. 33, p. 481-518, 1982.

TAIZ, L.; ZEIGER, E. Fisiologia vegetal. Tradução de Eliane Romanato Santarém et. al. 3. ed. Porto Alegre: Artmed, 2004. 719 p.

YODER, B. J.; DALEY, L. S. Development of a visible spectroscopic method for determining chlorophyll a and $\mathrm{b}$ in vivo in leaf samples. Spectroscopy, Amsterdam, v. 5, n. 8, p. 44-50, 1990. 
